\title{
Low-energy particle experiments-ion mass analyzer (LEPi) onboard the ERG (Arase) satellite
}

\author{
K. Asamura ${ }^{1 *} \mathbb{D}$, Y. Kazama², S. Yokota ${ }^{3}$ S. Kasahara ${ }^{4}$ and Y. Miyoshi ${ }^{5}$
}

\begin{abstract}
Low-energy ion experiments-ion mass analyzer (LEPi) is one of the particle instruments onboard the ERG satellite. LEPi is an ion energy-mass spectrometer which covers the range of particle energies from $<0.01$ to $25 \mathrm{keV} / \mathrm{q}$. Species of incoming ions are discriminated by a combination of electrostatic energy-per-charge analysis and the time-offlight technique. The sensor has a planar field-of-view, which provides $4 \pi$ steradian coverage by using the spin motion of the satellite. LEPi started its nominal observation after the initial checkout and commissioning phase in space.
\end{abstract}

Keywords: ERG satellite, lon analyzer

\section{Introduction}

The Exploration of energization and Radiation in Geospace (ERG) mission is designed to explore the plasma structure and the dynamics of the terrestrial inner magnetosphere. The scientific objectives of the mission include the understanding of the physical processes of acceleration, transportation, and loss of high-energy $(\sim$ $\mathrm{MeV}$ energy range) electrons in the inner magnetosphere, as well as understanding the evolution of geospace storms (Miyoshi et al. 2012, in review). LEPi is one of the ion analyzers onboard the ERG satellite. LEPi is designed to measure the three-dimensional velocity distribution functions of ions over an energy range of $<0.01-25 \mathrm{keV} / \mathrm{q}$ with species discrimination. The energy range of ion measurements on ERG is extended by the other ion analyzer, the medium-energy particle experiments-ion mass analyzer (MEPi) (Yokota et al. 2017), up to $180 \mathrm{keV} / \mathrm{q}$. Use of these two instruments covers the significant ion populations of the ring current, plasma sheet, and suprathermal component of the plasmasphere.

Ion distributions in the inner magnetosphere can affect the acceleration and loss of the high-energy electrons

\footnotetext{
*Correspondence: asamura@stp.isas.jaxa.jp

1 Japan Aerospace Exploration Agency, 3-1-1 Yoshinodai, Chuo,

Sagamihara 252-5210, Japan

Full list of author information is available at the end of the article
}

through excitation of electromagnetic plasma waves. Magnetosonic waves are excited by a ring distribution of protons with energies on the order of $10 \mathrm{keV}$ and with the energy comparable to the local Alfven energy (Horne et al. 2000; Chen et al. 2010; Jordanova et al. 2012; Ma et al. 2014). They can accelerate the electrons with energies between $\sim 10 \mathrm{keV}$ and a few $\mathrm{MeV}$ toward the $\mathrm{MeV}$ range (Horne et al. 2007). The excitation of electromagnetic ion cyclotron (EMIC) waves is associated with temperature anisotropy of ring current ions (Kennel and Petschek 1966; Shoji and Omura 2011; Shoji et al. 2017). EMIC waves cause the pitch angle scattering and loss of electrons from the magnetosphere in the $\mathrm{MeV}$ energy range and ions with energies on the order of $10 \mathrm{keV}$ (Thorne and Kennel 1971; Miyoshi et al. 2008). The characteristics of EMIC waves depend on the relative abundance of ions owing to the modification of dispersion relations. Through the measurements of ion fluxes as a function of energy, incoming direction, and species, observations of LEPi will be used to understand the wave-particle interactions that lead to acceleration and loss of various charged particles of the inner magnetosphere.

Both relative and absolute abundance of heavy ions (mainly $\mathrm{O}^{+}$) in the ring current tends to increase with geomagnetic activity. This change in ion composition affects the decay of the ring current because the life time 
of ions with the loss processes such as charge exchange, Coulomb collisions, and wave-particle interactions is species dependent (Fok et al. 1991; Daglis et al. 1999). Several species of these heavy ions are considered to be of ionospheric origin. The processes and paths of transportation of heavy ions from the ionosphere to the magnetosphere and the interplanetary space are still unknown. LEPi and MEPi will provide the species-discriminated ion flux of the ring current as a function of energy and pitch angles, which can be used to understand the dynamics of the ring current ions including escape and transport of heavy ions.

We describe the performance of LEPi and the initial observation results in this report.

\section{Instrumentation}

\section{Overview}

LEPi is mounted on the $+X$ panel of the satellite (Fig. 1), where it has planar field-of-view (FOV) in the $Y_{\mathrm{sc}} Z_{\mathrm{sc}}$ plane. Figure 2 shows the azimuthal channel definition of LEPi. The center of each channel is allocated at 22.5 deg separation forming a ring. Channels $0-8$ and e are wide channels whose angular width is $16 \mathrm{deg}$ (FWHM: full-width at half maximum), while channels 9-d are narrow channels with an angular width of 4 deg (FWHM). Full solid angle coverage is achieved by using channels $0-7$ with satellite spin motion whose axis is in the $\mathrm{Z}_{\mathrm{sc}}$ direction. Note that the FOV of LEPi covers mostly $2 \pi$ radian, although there are no channels around the $+Y_{\mathrm{sc}}$ direction. On the $+X$ panel, the high-energy electron experiments (HEPe) (Mitani et al. in review) and the medium-energy particle experiments-electron analyzer (MEPe) (Kasahara et al. 2018a) are also mounted. MEPe blocks a part of LEPi FOV; therefore, the corresponding channel is removed from LEPi. There are other FOV interference points with wire antennas and yokes of solar cell paddles. They slightly reduce the geometric factor of $\mathrm{LEPi}$, although the effects are minor.

LEPi is an ion energy-mass spectrometer that consists of three units, (1) an electrostatic energy-per-charge $(E / q)$ analyzer, (2) a time-of-flight (TOF) section, and (3) electronics. Figure 3 illustrates a schematic view of LEPi. The red arrow in panel (b) schematically indicates a trajectory of incident ions. Ions passing through the sensor aperture are $E / q$-filtered by the electrostatic field between the electrodes. Then, filtered ions are accelerated and transmitted through an ultra-thin carbon foil, and finally reach a detector (MCP: microchannel plate) in the TOF section. When particles are transmitted through the ultra-thin carbon foil, secondary electrons are emitted from the foil. These electrons are attracted and guided toward the MCP by the electrostatic field as schematically shown by a blue arrow in Fig. 3b. The time difference in the signal detection between the secondary electrons (START signal) and incident ions (STOP signal) is measured by the electronics as a TOF value that reflects the velocity of the incident ions. Then, the massper-charge $(M / q)$ of the incident ions is deduced with a combination of $E / q$ and TOF values.

Figure 4 shows a functional block diagram of LEPi. LEPi has 15 azimuthal channels, which discriminate the incoming directions of particles using a position-sensitive MCP assembly with a discrete anode system. Each channel contains MCP anodes for START and STOP signals separately. These signals are amplified by dedicated fast preamplifiers and the time interval of appearance timings between the START and STOP signals are measured by a time-to-digital converter (TDC). Then, the measured TOF values are sent to the field-programmable gate array (FPGA). The FPGA calculates $M / q$ for each particle detection event and increments the corresponding counter. Note that the FPGA knows the $E / q$ of the particles because the output level of the high-voltage power supply (HVPS) is controlled by the FPGA itself. Finally, the count data are sent to the CPU board.

The CPU board generates observation data packets based on the received count data. The generated data packets are compressed and sent to the data recorder operated by the satellite bus system through a telemetry/ command interface based on SpaceWire (Takashima et al. 2018). In addition to LEPi, the CPU board controls the low-energy particle experiments-electron analyzer (LEPe) (Kazama et al. 2017) via a command/data handling interface (SpaceWire). Onboard processing of LEPe raw data also occurs on the CPU board.

Specification and performance of LEPi are summarized in Table 1.

\section{Electrostatic analyzer (ESA)}

LEPi employs a top-hat-type electrostatic analyzer (Carlson et al. 1983) for the $E / q$ analysis. The ESA subsystem of LEPi was designed by a numerical simulation that calculated the trajectories of incident ions inside ESA as a function of incident angles, positions, and energies. An

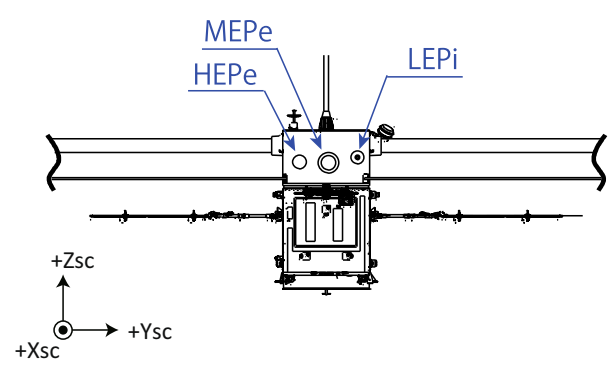

Fig. 1 Location of LEPi on ERG satellite. LEPi is mounted on the $+X$ panel 


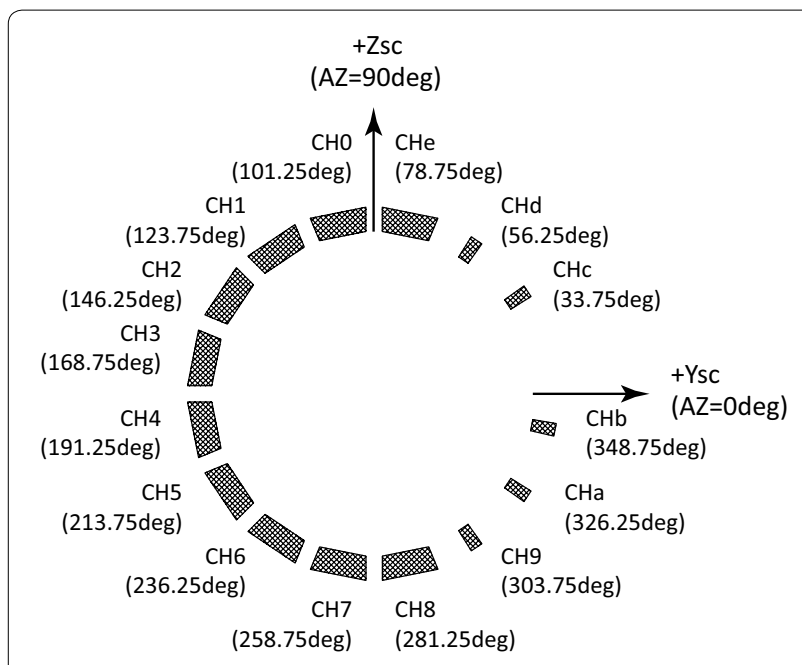

Fig. 2 Channel definition of LEPi. LEPi has a planar FOV in the $Y_{\mathrm{sc}} Z_{\mathrm{sc}}$ plane. Illustrated direction corresponds to the velocity direction of the incoming particles. Channels $0-8$, and e are wide channels, while channels 9-d are narrow channels. The positions of the center of the anodes in the satellite frame of reference are shown in parentheses

axis-symmetric model of the top-hat structure is applied for the numerical simulation. In general, the ion optics in the ESA linearly scales with the applied potential to the electrode (the inner dome in the LEPi case). However, the potential applied to the foil, which is the entrance of the TOF section, is a constant at $-4.9 \mathrm{kV}$ even if the inner dome potential varies. Therefore, the ion optics in ESA is slightly changed with the inner dome potential. The geometric factor $G_{\mathrm{ESA}}$ of LEPi as a function of $E / q$ is shown in Fig. 5, which is derived from the numerical simulation.

The top-hat-type analyzer provides a $360 \mathrm{deg}$ planar FOV in principle. The incoming direction of the particles can be determined by the exit positions of the particles from the ESA section. The exit area can be a plane for all the azimuthal channels because the deflection angles of particle trajectories are $\sim 90 \mathrm{deg}$ (see Fig. 3b). Figure 6 shows the azimuthal angle response of LEPi, obtained by proton beams with the energy of $12 \mathrm{keV}$ in the laboratory. Responses of wide (67.5 deg-292.5 deg) and narrow channels (292.5 deg-0 deg and $22.5 \mathrm{deg}-67.5 \mathrm{deg}$ ) are illustrated in Fig. 6. Since the foils are located at the exit of the ESA section (i.e., the entrance of the TOF section), the hit position of incoming ions on the foil reflects the incoming direction of the ions at the sensor aperture. The narrow channels are designed by applying the foils with the narrow width in the azimuthal direction (Fig. 7).

Figure 8 shows the energy-incident elevation angle response of LEPi (azimuthal channel 4: wide channel and 9: narrow channel) for proton beams with the energy of $12 \mathrm{keV}$, obtained in laboratory experiments. There is no significant difference between wide and narrow channels. The ratio of the average energy-to-the applied voltage to the inner dome (analyzer constant) is 5.0. The width of the elevation angle response is $4.5 \mathrm{deg}$ and 4.3 deg (FWHM) for channels 4 and 9, respectively, which are much smaller than both the azimuthal angle separation (22.5 deg) and the spin phase interval (22.5 deg in the normal case). The FOV direction moves during the energy scan due to the satellite spin motion. Because of the smaller width of the elevation angle response than the phase interval, LEPi may potentially miss narrow particle distributions such as ionospheric outflows. Energy resolution (width of energy response relative to mean energy) is 0.13 (FWHM).

Table 2 shows a normal $E / q$ setting of the energy sweep on LEPi. The same value is assigned to energy steps 0 and 1 because it takes a longer time to stabilize the applied voltage when it changes from almost zero to $-5 \mathrm{kV}$. As

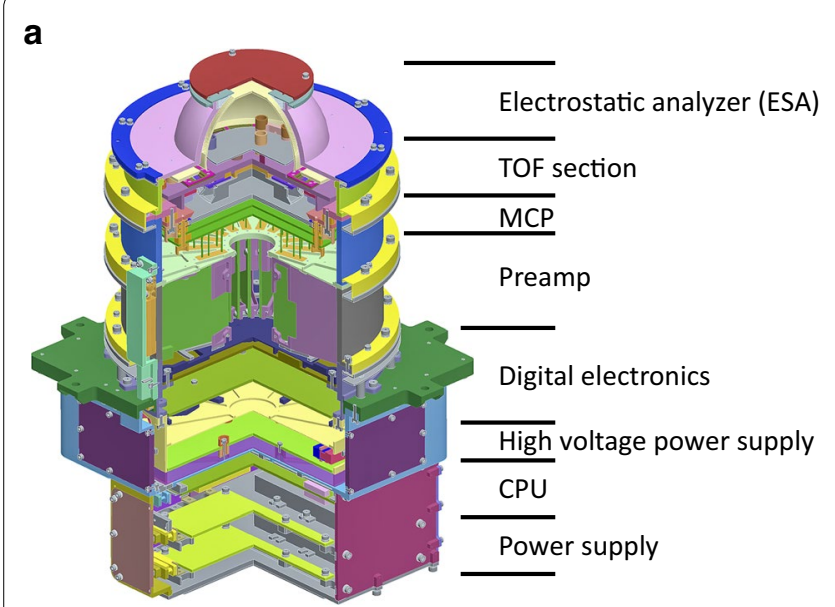

b

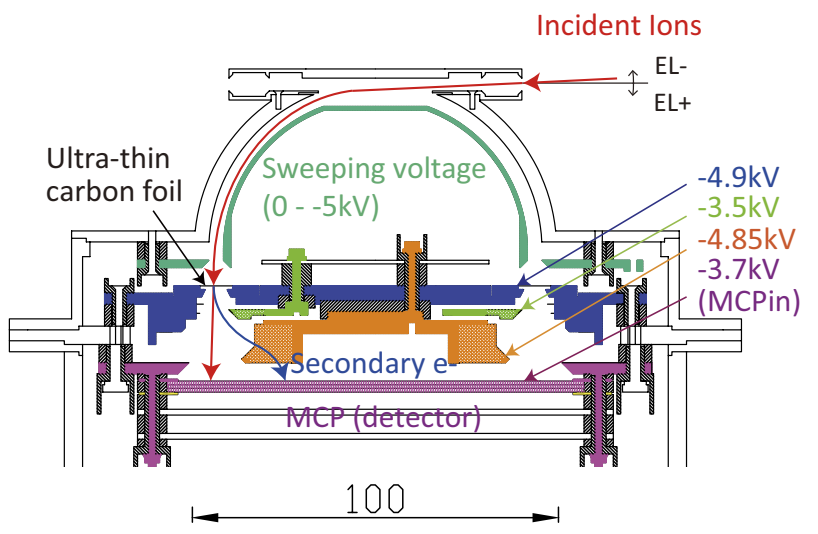

Fig. 3 Shape of LEPi. a 3D view with a partial cut. b Sectional view of the sensor part 


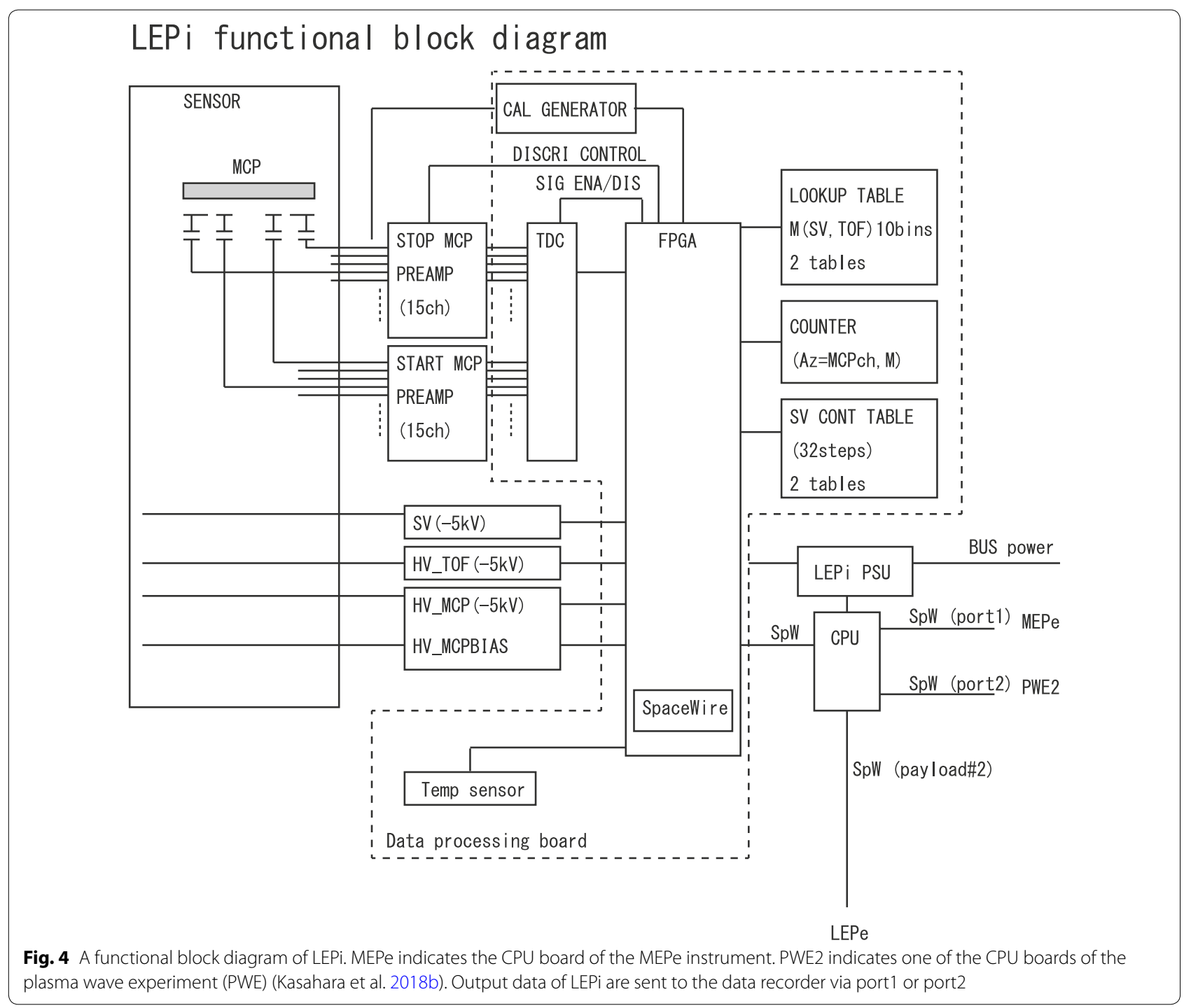

a result, particles with lower energies can contaminate the energy step 0. Assigned energies of steps 30 and 31 do not appear in Table 2 because the applied voltages of these steps are slightly positive. These steps can be used for monitoring the background count rate.

Measurement timing of LEPi is determined by the reception timing of the index pulse generated in the attitude control system of the satellite based on the Sunacquisition timing of the spin-type Sun aspect sensor (SSAS). Coincident measurements by all the instruments onboard the satellite are achieved with a notification system of the index pulse timing, which is simultaneously sent to each instrument once per spin. The spin period is determined by onboard calculations of the time interval between the latest two index pulse receptions for every spin. The calculated spin period is automatically divided into 16 phases in LEPi, as schematically shown in Fig. 9. In each phase, the applied voltage to the inner dome of the electrostatic analyzer (see Fig. 3b) is swept with 32 steps to obtain the energy spectra of incident particles. Since the nominal spin rate of the ERG satellite is $8 \mathrm{~s}$, the time period for each energy step is nominally $15.6 \mathrm{~ms}[(=$ $8 /(16 \times 32)]$. Note that the first $1 \mathrm{~ms}$ of each energy step is regarded as a dead time to wait for the stabilization of the high-voltage output. Therefore, the nominal data accumulation time is $14.6 \mathrm{~ms}(=15.6-1)$. As a result, under normal observations, LEPi obtains 16 energy spectra for every azimuthal channel in a spin, receiving threedimensional velocity distribution functions of incident particles. 
Table 1 Specification and performance of LEPi

\begin{tabular}{|c|c|c|c|}
\hline Parameter & Value & Unit & Notes \\
\hline Energy range & $<0.01-25$ & $\mathrm{keV} / \mathrm{q}$ & \\
\hline \multirow[t]{2}{*}{ Energy resolution } & $0.16 @ 0.01 \mathrm{keV} / \mathrm{q}$ & & $\Delta E / E$ \\
\hline & $0.13 @ 12$ keV/q & & $\Delta E / E$ \\
\hline Analyzer constant & 5.0 & & \\
\hline Inner dome radius & 41.5 & $\mathrm{~mm}$ & Electrode in ESA \\
\hline Outer dome radius & 45.5 & $\mathrm{~mm}$ & Electrode in ESA \\
\hline \multirow[t]{3}{*}{ Mass discrimination } & $\mathrm{H}^{+}, \mathrm{H}_{2}^{+} / \mathrm{He}^{++}, \mathrm{He}^{+}$ & & \\
\hline & $\mathrm{N}^{++} / \mathrm{O}^{++}, \mathrm{N}^{+} / \mathrm{O}^{+}$ & & \\
\hline & $\mathrm{N}_{2}^{+} \mathrm{NO}^{+} / \mathrm{O}_{2}^{+}$ & & \\
\hline Post-acceleration potential & -4.9 & $\mathrm{kV}$ & Foil potential \\
\hline Length of TOF drift path & 26 & $\mathrm{~mm}$ & \\
\hline FOV & $310 \times 4.5$ & $\operatorname{deg} \times \operatorname{deg}$ & FWHM \\
\hline \multirow[t]{2}{*}{ Angle response of azimuthal channels } & 16.0 & deg & FWHM, wide channel \\
\hline & 4.3 & deg & FWHM, narrow channel \\
\hline Separation of azimuthal channels & 22.5 & deg & \\
\hline \multirow[t]{4}{*}{ Geometric factor } & $1.7 @ 0.01 \mathrm{keV} / \mathrm{q}$ & $10^{-3} \mathrm{~cm}^{2} \mathrm{str} \mathrm{keV} / \mathrm{keV} / \mathrm{channel}$ & Wide channel \\
\hline & $1.4 @ 12$ keV/q & $10^{-3} \mathrm{~cm}^{2} \mathrm{str} \mathrm{keV} / \mathrm{keV} / \mathrm{channel}$ & Wide channel \\
\hline & $0.40 @ 0.01$ keV/q & $10^{-3} \mathrm{~cm}^{2} \operatorname{str} \mathrm{keV} / \mathrm{keV} / \mathrm{channel}$ & Narrow channel \\
\hline & $0.32 @ 12$ keV/q & $10^{-3} \mathrm{~cm}^{2} \mathrm{str} \mathrm{keV} / \mathrm{keV} /$ channel & Narrow channel \\
\hline Number of energy steps & 32 & & \\
\hline \multirow[t]{2}{*}{ Number of mass bins } & $1-8$ & & Normal mode, commandable \\
\hline & $1-509$ & & TOF mode, commandable \\
\hline \multirow[t]{2}{*}{ Number of azimuthal bins } & $1-15$ & & Normal mode, commandable \\
\hline & 1 & & TOF mode \\
\hline \multirow[t]{2}{*}{ Number of spin phase bins } & $1-16$ & & Normal mode, commandable \\
\hline & $1-4$ & & TOF mode, commandable \\
\hline Time resolution & $1-65,536$ & Satellite spin (nominal spin period: $8 \mathrm{~s}$ ) & $\begin{array}{l}\text { Full 3D observation both for normal and TOF } \\
\text { modes commandable }\end{array}$ \\
\hline Dead time & 1 & ms/energy step & Commandable \\
\hline Sensor size & $235 \times 235 \times 362$ & $\mathrm{~mm} \times \mathrm{mm} \times \mathrm{mm}$ & \\
\hline Sensor mass & 6.94 & $\mathrm{~kg}$ & \\
\hline Power consumption & 23.8 & W & Primary side \\
\hline
\end{tabular}

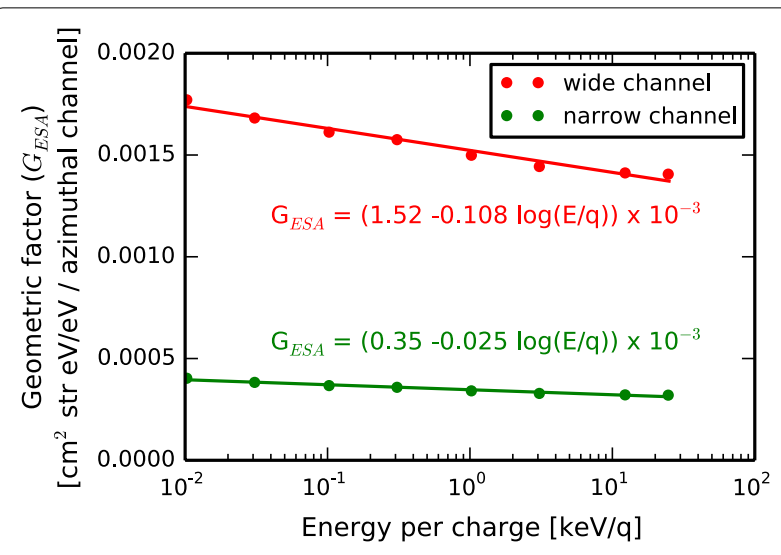

Fig. 5 The geometric factor (GESA) for wide (red) and narrow (green) channels. The lines are obtained by the least square fitting

\section{Time-of-flight (TOF) analysis}

In TOF analysis, the velocity of the incoming particle is identified by measuring the elapsed time between the two signals (START and STOP signals). For the START signal, secondary electrons released at the passage of incoming particles through an ultra-thin carbon foil (thickness is $\sim 5 \mathrm{~nm}$ ) are used. The incoming particle itself hits a detector after passing through the foil and this is then used as the STOP signal. This type of spectrometer has been employed in many space applications (Gloeckler and Hsieh 1979; Wurz 2000). The TOF analysis is a coincidence measurement because it requires multiple (START and STOP in the case of LEPi) signals for a successful identification of a particle. Moreover, a combination of $E / q$ and TOF analysis sets a window of 


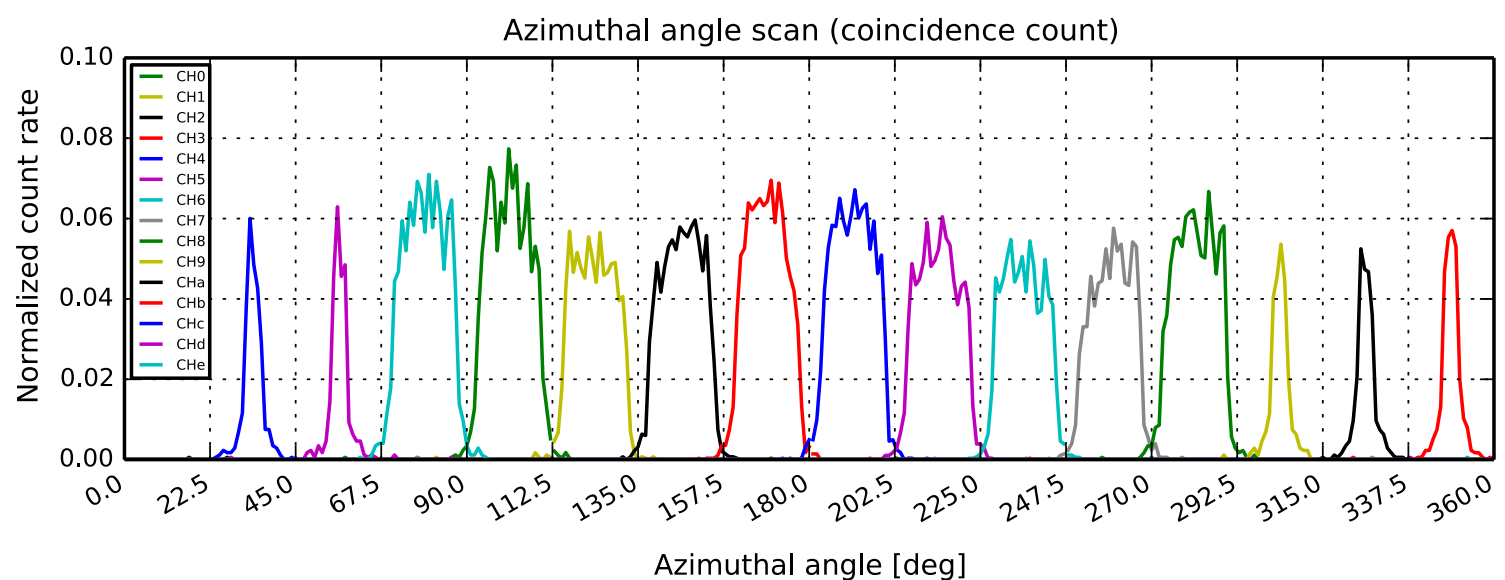

Fig. 6 Azimuthal angle response obtained in laboratory experiments. Proton beams with the energy of $12 \mathrm{keV}$ are used. 0 deg and 90 deg coincide with $+Y_{s c}$ and $+Z_{s c}$ directions, respectively (see Figs. 1, 2)

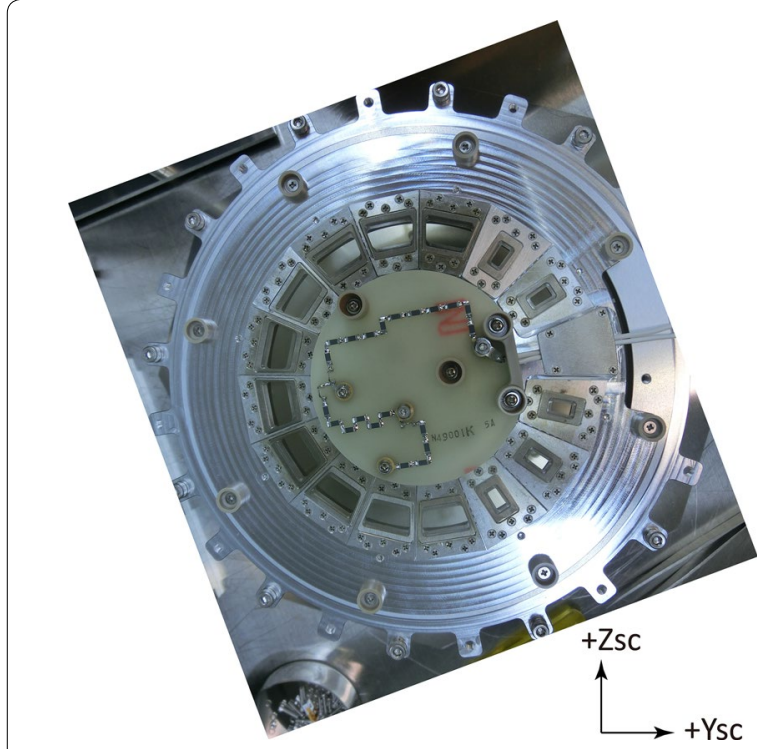

Fig. 7 Picture of the entrance of the TOF section. Foil holders with ultra-thin carbon foils are installed at the entrance

allowable TOF values depending on the species of incoming particles. Therefore, the TOF analysis can discriminate the target particles of LEPi against the background high-energy particles and photons such as ultraviolet radiation coming from the Sun and the geocorona $(\mathrm{H}$ Lyman- $\alpha$ ) because they mostly generate the START or the STOP signal but seldom generate both signals. Even if they generate both the START and STOP signals, their TOF is too short and outside the TOF window. However, there can be an accidental coincidence where a particle/ photon creates a START signal and another particle/photon generates a STOP signal. Based on the assumption that the signal detection rate follows a Poisson distribution, the occurrence rate of the accidental coincidence can be expressed as

$$
C_{\text {false }}=C_{\text {start }}\left\{1-\exp \left(-C_{\text {stop }} \Delta T\right)\right\}
$$

where $C_{\text {false }}, C_{\text {start }}, C_{\text {stop }}$, and $\Delta T$ are the occurrence rates of the accidental coincidence, START count rate, STOP count rate, and the period of allowable TOF window, respectively. In the case of $\mathrm{LEPi}, \Delta T$ is $\sim 250 \mathrm{~ns}$, which covers the species ranging from protons to molecular ions such as $\mathrm{N}_{2}^{+}$, $\mathrm{NO}^{+}$, and $\mathrm{O}_{2}^{+}$.

In order to reduce the background noise, the areal size of the MCP anodes should be minimized. In LEPi, trajectories of the secondary electrons are guided toward the radially inward portion of the MCP input surface by an electrostatic field, as schematically shown in Fig. 10a, b. Their trajectories are focused near the MCP input surface, resulting in a small areal size of the START anode $\left(0.25 \mathrm{~cm}^{2}\right.$ per azimuthal channel), using the non-axisymmetric design of electrodes. In contrast, the trajectories of the incoming ions are difficult to control because a significant fraction of ions passing through the ultra-thin carbon foil is converted to neutrals (Bürgi et al. 1990; Funsten et al. 1993). Therefore, the STOP anode is rather large $\left(1.66 \mathrm{~cm}^{2}\right.$ per azimuthal channel). For reference, the design of the MCP anodes is illustrated in Fig. 10c.

Based on the laboratory experiments, TOF profiles of $\mathrm{H}^{+}, \mathrm{H}_{2}^{+} / \mathrm{He}^{++}, \mathrm{He}^{+}, \mathrm{N}^{++}, \mathrm{N}^{+}$, and $\mathrm{N}_{2}^{+}$with energies of $12,4,2$, and $0.1 \mathrm{keV} / \mathrm{q}$ are shown in Fig. 11. These ions are evidently discriminated, although their TOF values are shortened with increasing energies (i.e., increasing velocities). Note that, to measure the ions with energies of $0.1 \mathrm{keV} / \mathrm{q}$, ion beams with energies of $1.1 \mathrm{keV} / \mathrm{q}$ are used because of the limitations of the facility. Instead, 

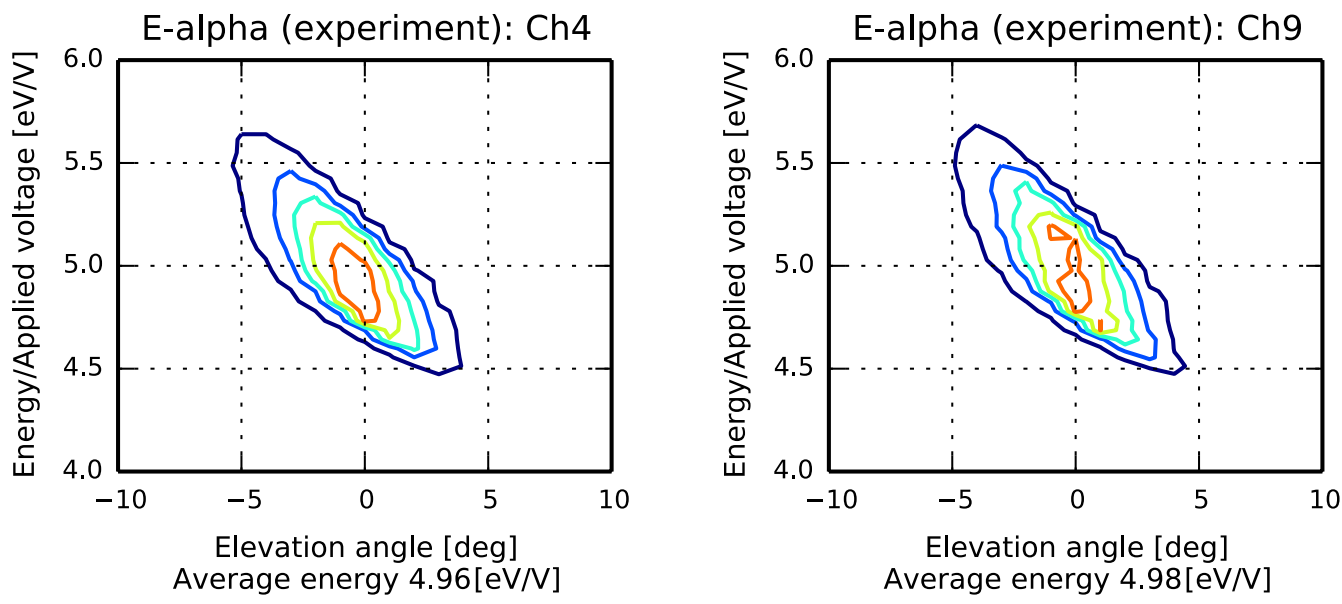

Fig. 8 Energy-elevation angle response of LEPi obtained in laboratory experiments. Responses of azimuthal channel 4 (wide channel) and 9 (narrow channel) for proton beams with the energy of $12 \mathrm{keV}$ are shown. Contour lines correspond to 5 (blue), 25 (light-blue), 45 (cyan), 65 (yellow), and $85 \%$ (orange) of the maximum sensitivity level. Negative voltage is applied to the inner dome of the analyzer to measure the positively charged ions, although the energy per applied voltage in the figure is expressed as positive

Table 2 E/q setting of energy sweep

\begin{tabular}{lcclll}
\hline Energy step & $\boldsymbol{E} / \boldsymbol{q}[\mathrm{eV} / \mathbf{q}]$ & Notes & Energy step & $\boldsymbol{E} / \boldsymbol{q}[\mathrm{eV} / \mathbf{q}]$ & Notes \\
\hline 0 & 25,100 & $\left.{ }^{*} 1\right)$ & 16 & 356 & \\
1 & 25,100 & & 17 & 268 & \\
2 & 19,200 & 18 & 201 & \\
3 & 14,400 & 19 & 152 & \\
4 & 10,900 & 20 & 114 & \\
5 & 8160 & 21 & 86 & \\
6 & 6140 & 22 & 65 & \\
7 & 4620 & 23 & 49 & \\
8 & 3470 & 24 & 36 & \\
9 & 2610 & 25 & 29 & \\
10 & 1970 & 26 & 23 & \\
11 & 1480 & 27 & 17 & \\
12 & 1110 & 28 & 10 & \\
13 & 836 & 29 & 4 & \\
14 & 629 & 30 & & $(* 1)$ \\
15 & 473 & 31 & & $\left({ }^{*} 1\right)$ \\
\hline
\end{tabular}

(*1) Not used for observation

the voltage applied to the foil is increased from -44.9 to $-3.9 \mathrm{kV}$. For the other electrodes in the TOF section, voltages are applied with a resistive divider (shown in the center of the picture in Fig. 7), resulting in voltages multiplied by $3.9 / 4.9(=0.80)$ relative to the original ones. Therefore, even if the ion beams with the energy of $1.1 \mathrm{keV} / \mathrm{q}$ are used, the energy of the ions in front of the foil are the same as the case of the ion beams with the energy of $0.1 \mathrm{keV} / \mathrm{q}$ for the original voltage configuration. Note that, for a foil voltage of $-3.9 \mathrm{kV}$, all the voltages applied to the electrodes in the TOF section should be increased by $1 \mathrm{kV}$ to have the same electric field strength as in the case of foil voltage of $-4.9 \mathrm{kV}$. However, in order to avoid difficulties on sensor disassembling, the voltage reduction to $80 \%$ is chosen. There is a satisfactory agreement between the TOF spectrum of $0.9 \mathrm{keV}$ proton beam with $-4.9 \mathrm{kV}$ applied to the foil and that of $1.9 \mathrm{keV}$ protons with $-3.9 \mathrm{kV}$ applied to the foil where the whole voltage in the TOF section is reduced by $80 \%$.

Two TDCs are used in LEPi. One of them handles the output signals of the preamplifiers for eight azimuthal channels (c-e, 0-4), and the other handles those for seven azimuthal channels (5-9, a, b). When signals reach the TDC, timing information is recorded in TDC, and read by FPGA, which calculates the time interval between the START and STOP signals. This process takes $\sim 2 \mu \mathrm{s}$. Therefore, the maximum signal processing rate is $\sim 5 \times 10^{5}$ [count/s/8(7) azimuthal channels], which is $\sim 7 \times 10^{3}$ [count/energy step/8(7) azimuthal channels] for the satellite spin rate of $8 \mathrm{~s}$. Note that, each azimuthal channel has an octuple input buffer for the TOF calculation. In LEPi, each azimuthal channel has a dedicated counter for accumulating the number of events that cannot be processed by TDC + FPGA because of the exceptionally high input rate. These count data are attached to the observation data for every energy step and sent to the ground.

\section{Detection efficiency}

One can calculate the absolute detection efficiencies of START signals, STOP signals, and coincidence events, although the TOF section includes complex parameters 


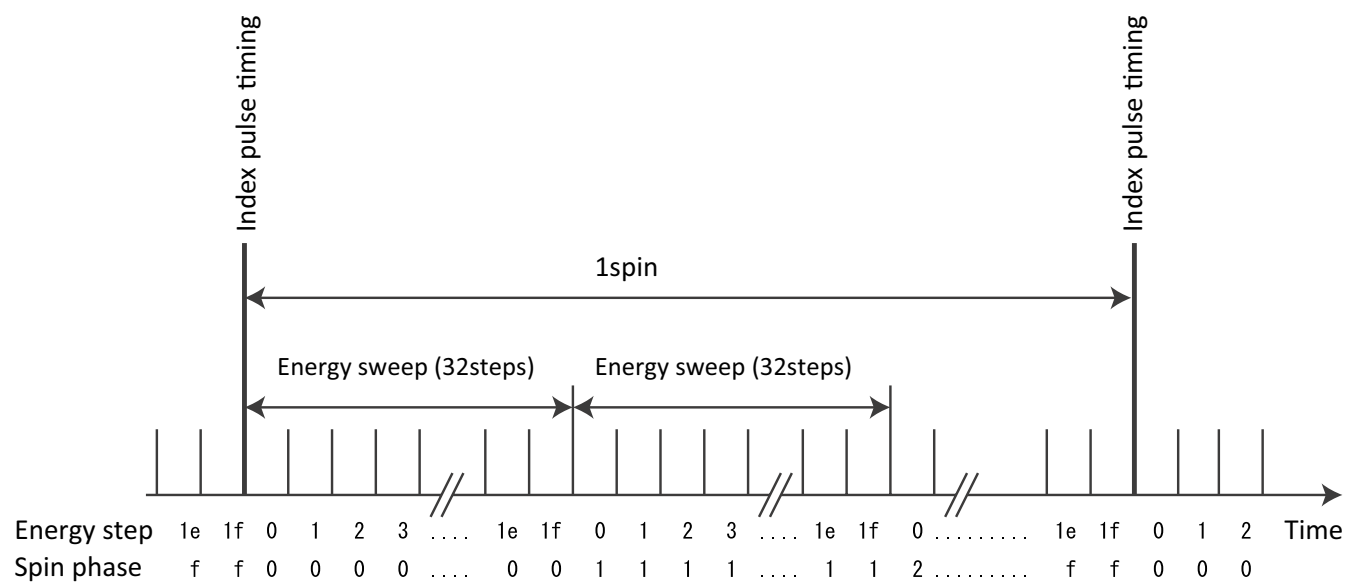

Fig. 9 Measurement timing of LEPi with the index pulse. Spin phase is determined by the reception timing of the index pulse

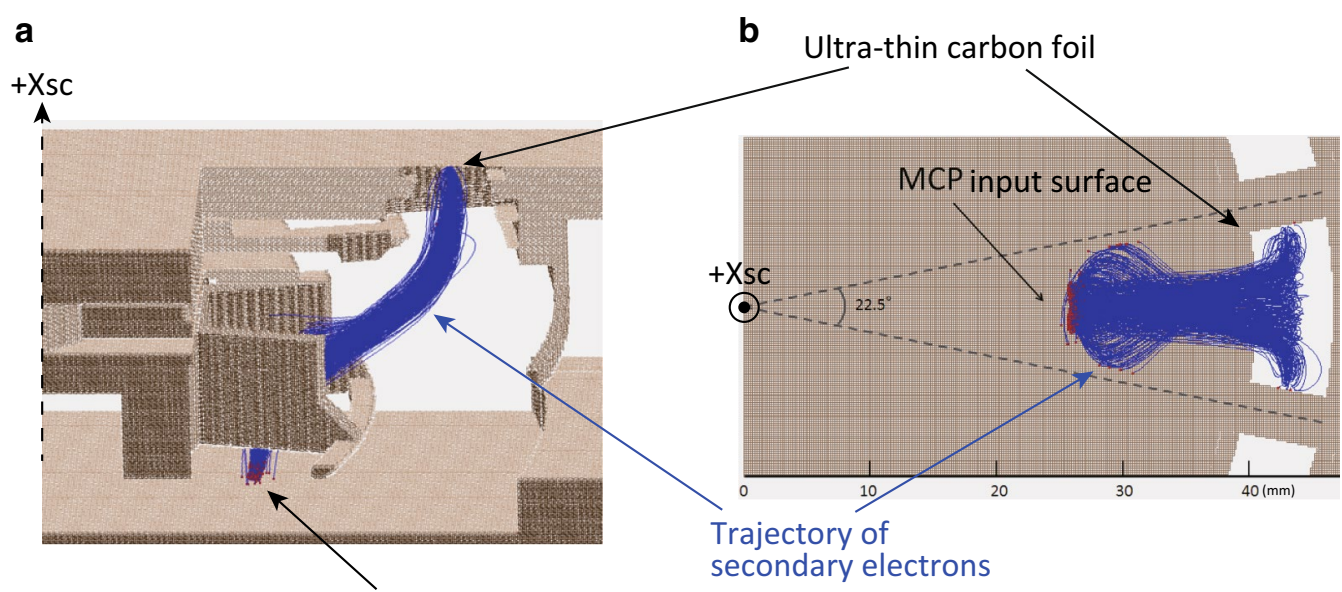

MCP input surface

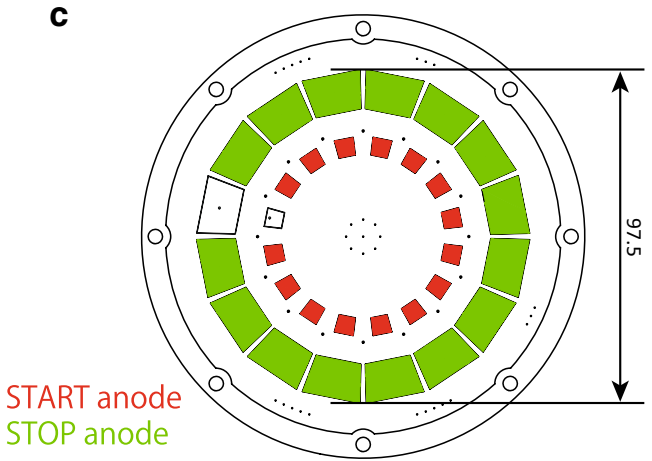

Fig. 10 Shape of the MCP anode and sample trajectories of secondary electrons emitted from the ultra-thin carbon foil. a Cut-away view of the TOF section. Brown area indicates electrodes. Sample trajectories of the secondary electrons are drawn in blue lines. Red points indicate the reach points of the particles. b Same as a but horizontal view of the TOF section. Foil area is indicated in white. c Shape of the MCP anode. Red and green areas indicate START and STOP anodes, respectively

such as secondary electron/incident ion trajectories, the emission efficiency of secondary electrons, and particle detection efficiencies of the MCP. The detection efficiencies for each azimuthal channel are simply calculated as

$$
\varepsilon_{\text {start }}=C_{\text {coin }} / C_{\text {stop }}
$$



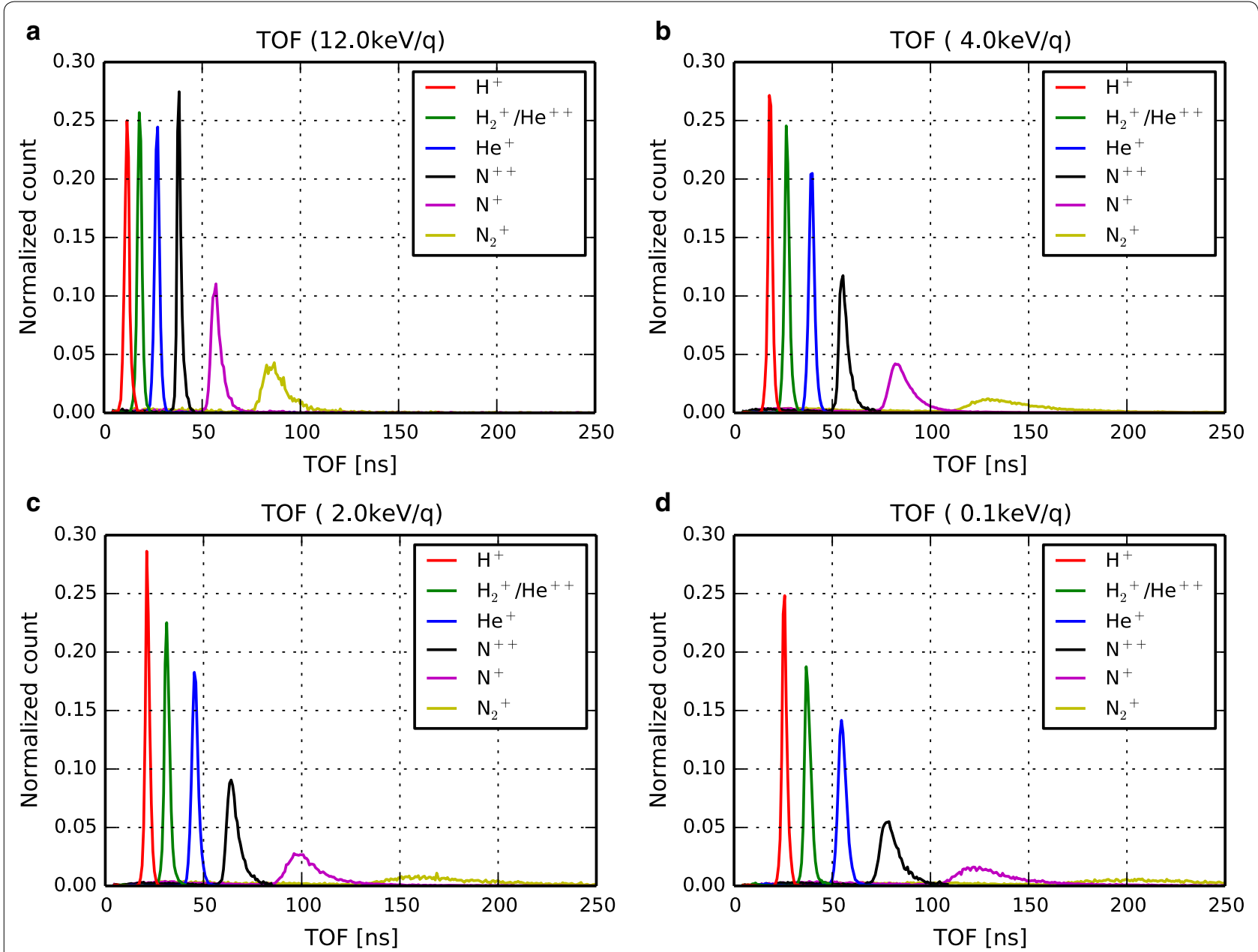

Fig. 11 TOF profiles of azimuthal channel 3 obtained by laboratory experiments. a Response for ion beams with energies of $12 \mathrm{keV} / \mathrm{q}, \mathbf{b} 4 \mathrm{keV} / \mathrm{q}$, c $2 \mathrm{keV} / \mathrm{q}$, and d $0.1 \mathrm{keV} / \mathrm{q}$

$$
\begin{aligned}
& \varepsilon_{\text {stop }}=C_{\text {coin }} / C_{\text {start }} \\
& \varepsilon_{\text {coin }}=\varepsilon_{\text {start }} \varepsilon_{\text {stop }}
\end{aligned}
$$

where $\varepsilon_{\text {start }}, \varepsilon_{\text {stop }}, \varepsilon_{\text {coin }}$, and $C_{\text {coin }}$ are the detection efficiencies of START signals, STOP signals, coincidence events, and coincidence count rate, respectively (Gruntman and Morozov 1982; Funsten et al. 2005, 2013). Based on this method, typical detection efficiencies observed in laboratory experiments are shown in Fig. 12. However, the detection efficiencies change over the lifetime of the mission. For example, the MCP gain typically decreases with increasing cumulated count. In order to monitor the detection efficiencies during the mission, $C_{\text {start }}$ and $C_{\text {stop }}$ are reported for all the azimuthal channels throughout the mission. The count rate of noise should be negligibly small when $\varepsilon_{\text {start }}, \varepsilon_{\text {stop }}$, and $\varepsilon_{\text {coin }}$ are calculated using this method.

\section{Operation}

LEPi has two observation modes, normal mode and TOF mode. Figure 13 illustrates a block diagram of onboard data processing. In the normal mode, the $M / q$ of the particles is determined by the onboard data processing as a mass index. When a particle is detected, the mass index is calculated by referring to a table with a corresponding energy step, energy sweep table, and measured TOF step. Then, the onboard counter is incremented as a function of energy step, mass index, and azimuthal sector, forming a counter matrix. The generated counter matrix is sent to the CPU board, where the CPU adds information of the spin phase and sends the data to the satellite bus system. In the normal mode, LEPi can obtain 16 energy spectra for every azimuthal channel in a satellite spin, providing three-dimensional velocity distribution functions of ions once per spin. In the TOF mode, raw measured TOF values are used instead of the mass index. In this mode, only a part of observed data can be sent to the satellite bus 
system because there are 509 TOF steps in total, much larger than the number of the mass indices (maximum $8)$. Therefore, all the available azimuthal channels are treated as one channel (data are summed up), and generated energy spectra are sent at most once per four spin phases. In order to obtain one energy spectrum in four spin phases, 32 energy steps are selected in $128(=4 \times$ 32) steps, where rest of them are discarded (Fig. 14). In the TOF mode, $C_{\text {start }}, C_{\text {stop }}$, and $C_{\text {coin }}$ of each azimuthal channel and the energy step are attached to the generated energy spectra.

Currently, LEPi is operated in the normal mode most of the time, while the TOF mode is inserted intermittently. Mode scheduling is 3.5 revolutions around the Earth for the normal mode, and then, 0.5 revolution (outbound pass) for the TOF mode, alternating repeatedly. The energy sweep profile currently used for both normal and TOF modes is the same (Table 2).

\section{Initial observation results}

On March 23, 2017, all the scientific instruments including LEPi started their nominal observations after the initial checkout and commissioning phase. Figure 15 shows the 1-day stacked plot of the energy-time diagram, Lm (Mcllwain L), AL, and Sym-H indices on May 28, 2017 when a magnetic storm occurred. The energy-time diagrams show the detected count rate of the protons, $\mathrm{O}^{+}$ $/ \mathrm{N}^{+}$, and $\mathrm{He}^{+}$. The observation mode of LEPi is shown at the top of the panels. Observation of LEPi is suspended around the perigee of the satellite trajectory (0538 and
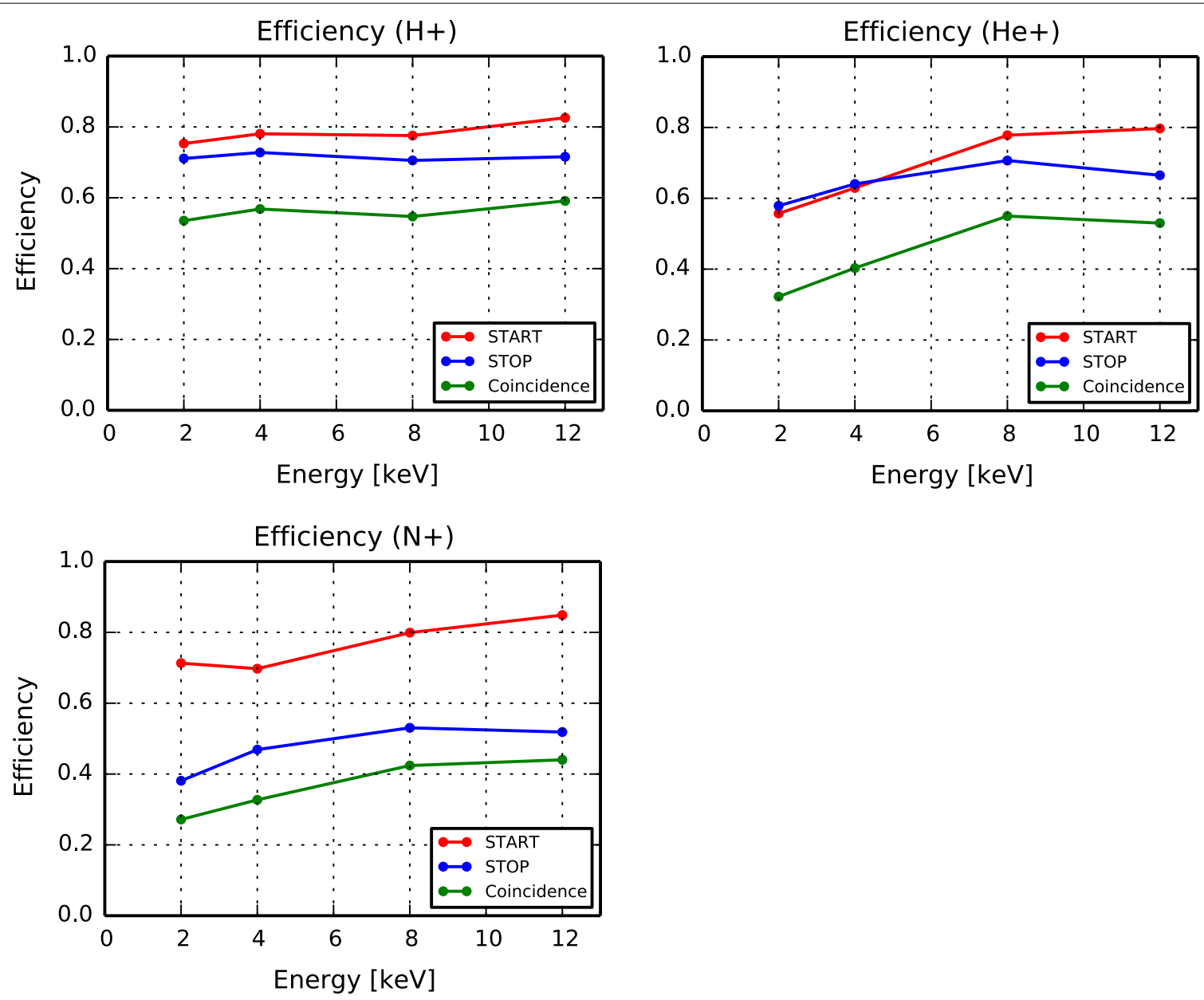

Fig. 12 Typical detection efficiencies of azimuthal channel 3 for incident ions (STOP) and secondary electrons (START) based on the laboratory experiment. The coincidence efficiency is the product of START and STOP efficiencies 


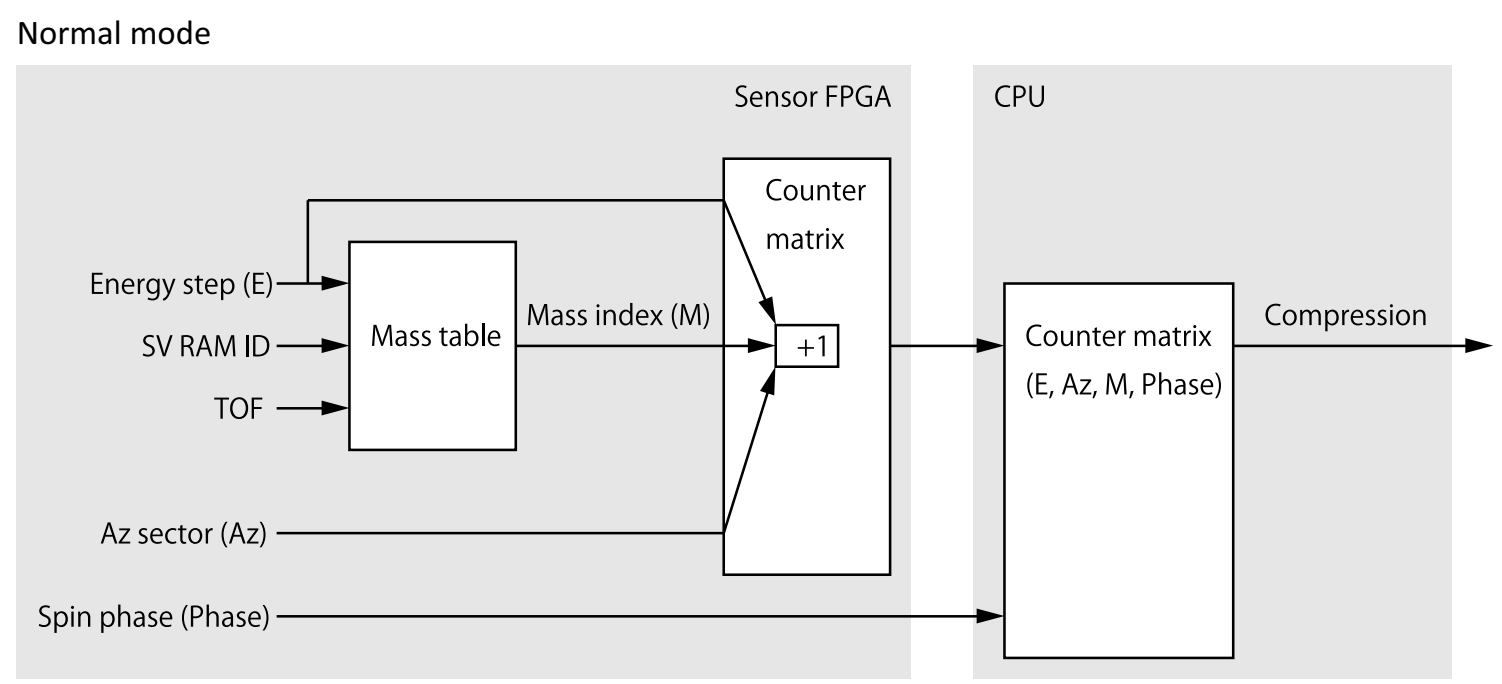

\section{TOF mode}

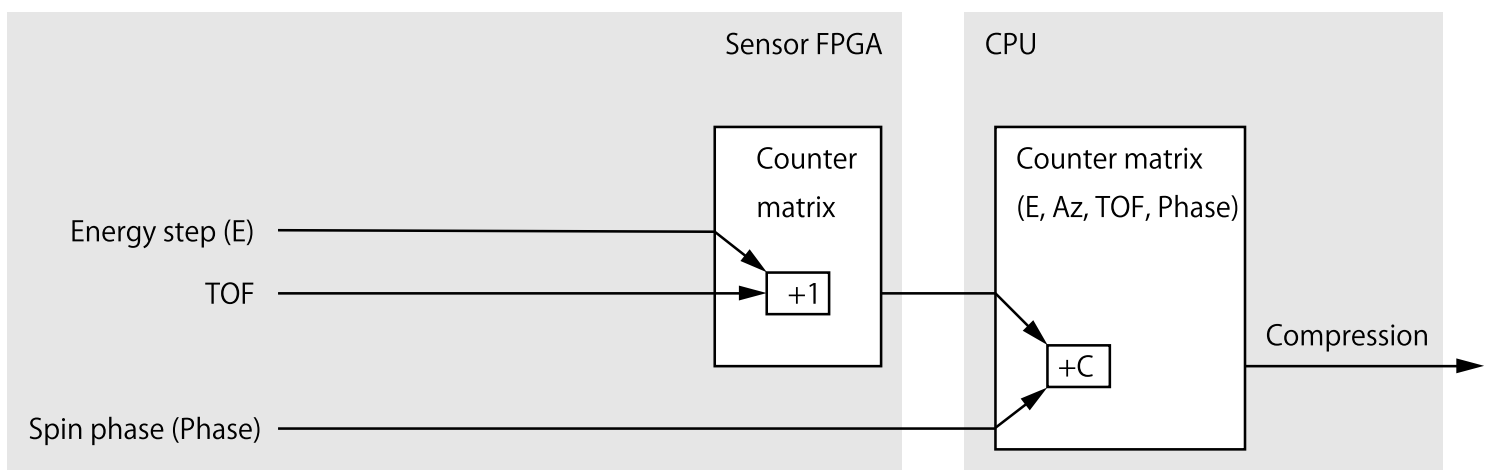

Fig. 13 Block diagram of onboard data processing. There are two observation modes on LEPi

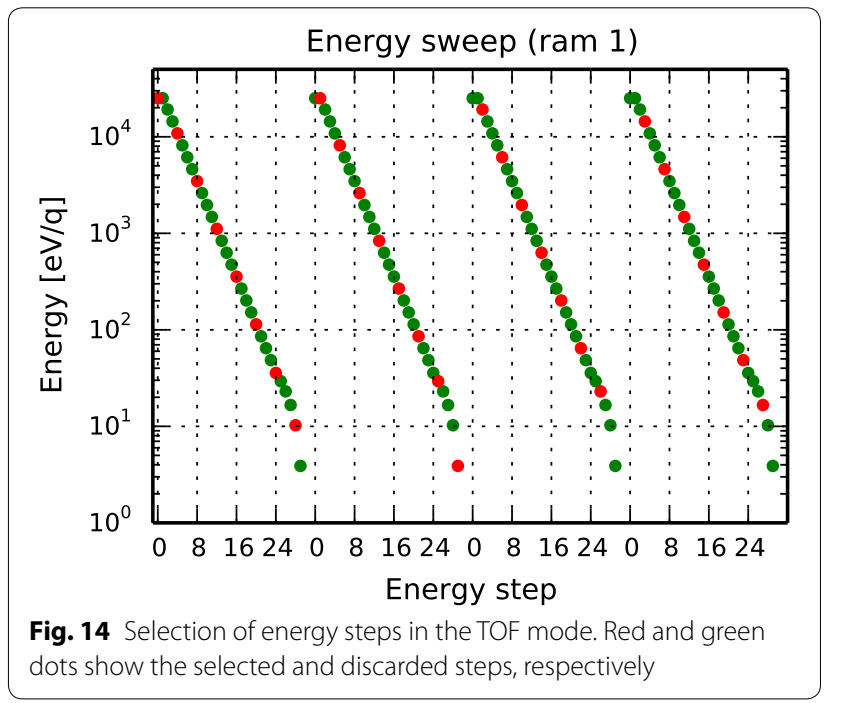

1506 UT in case of Fig. 15) by ramping down all the high-voltage output to avoid the intense flux of cold ions in the dense plasmasphere/ionosphere. Despite the suspension of observation around the perigee, the intense fluxes of cold ions at energy levels lower than $20 \mathrm{eV} / \mathrm{q}$ are still detected in low altitudes where $\mathrm{Lm}$ is $\sim 2(\sim 0510$, 0550, 1450, and 1520 UT). Figure 16 shows the pitch angle-time diagram of the protons with energy levels of $19,200,1110$, and $114 \mathrm{eV}$. The pitch angle distribution is not shown when LEPi is in the TOF mode. The calculation of pitch angles with species discrimination is difficult for the TOF data because the data of all the available azimuthal channels are basically summed up in the TOF mode.

When foil-based TOF techniques such as LEPi are used, there are START signals that have no coincident STOP signals (START ONLY event) and vice versa (STOP ONLY event). If we assume that the background count rate is unchanged within one energy sweep, the 


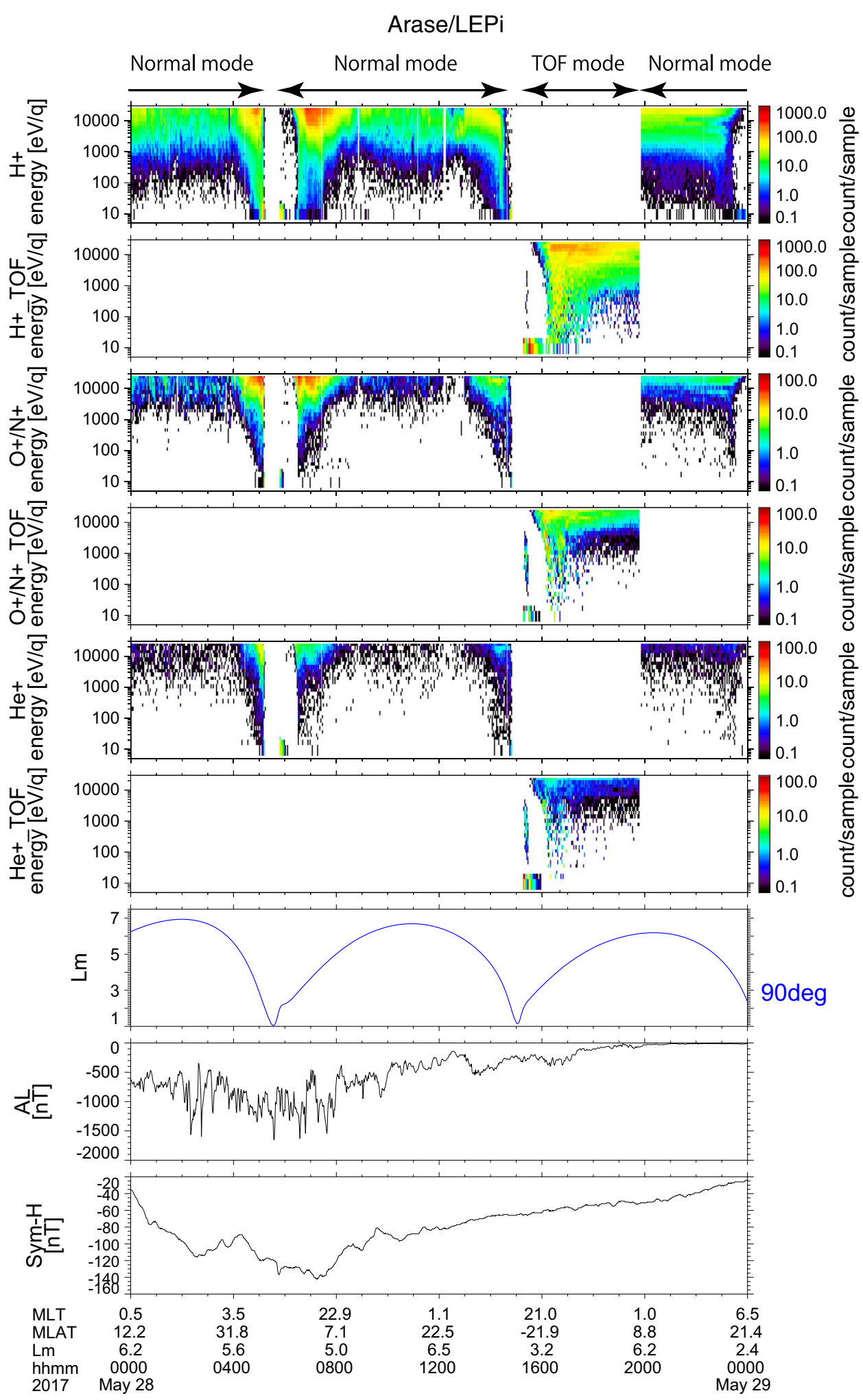

Fig. 15 Energy-time diagram of the count rate of $\mathrm{H}^{+}, \mathrm{O}^{+} / \mathrm{N}^{+}$, and He $\mathrm{H}^{+}$observed by LEPi on May 28, 2017. Lm, AL, and Sym-H indices are also shown. AL and Sym-H indices indicate the strongest current intensity of westward auroral electrojets and a measure of geomagnetic disturbance, respectively 

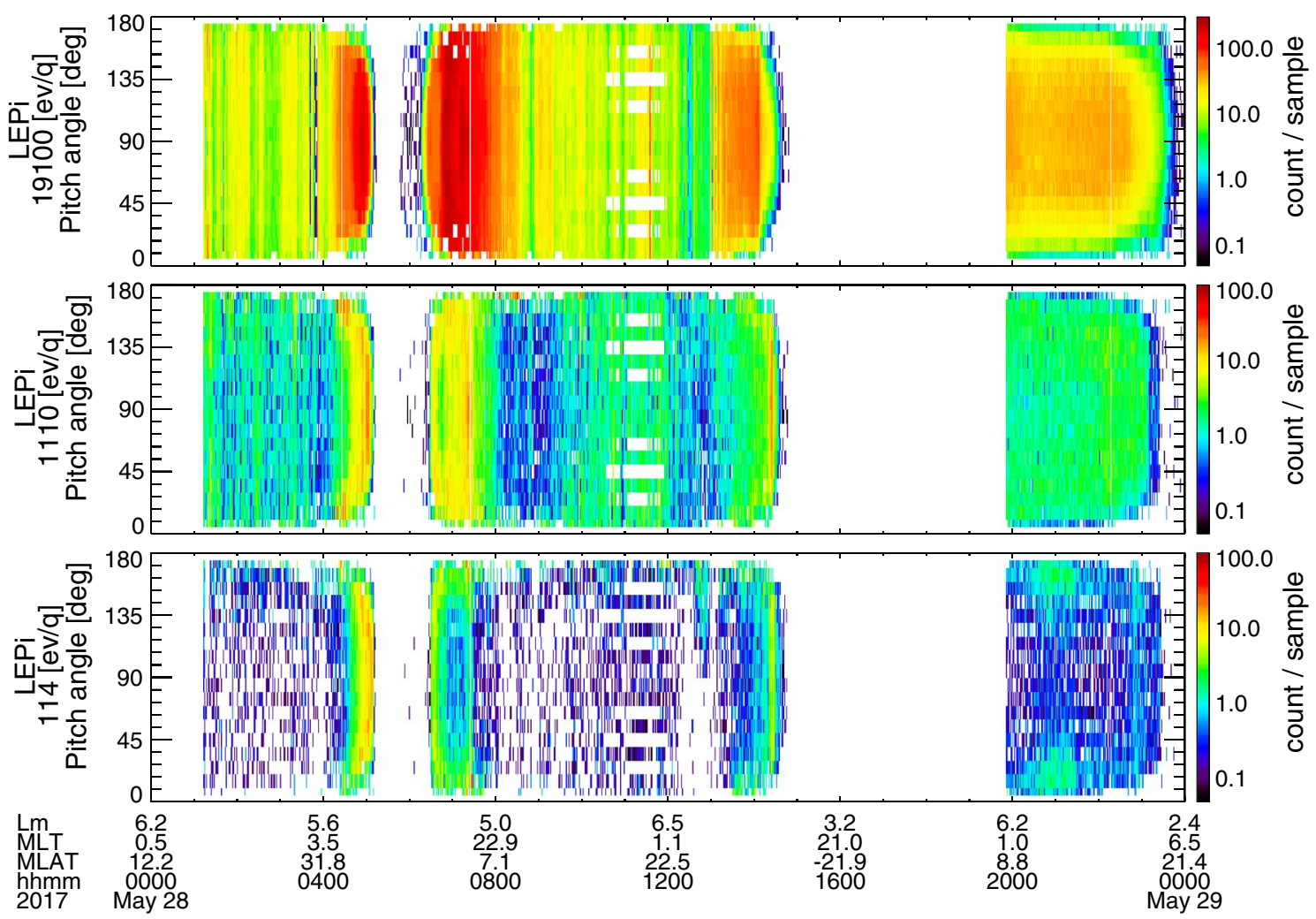

Fig. 16 Pitch angle-time plot for the protons with energies of 19,200, 1110, and $114 \mathrm{eV}$. Time period of the plot is the same as that of Fig. 15
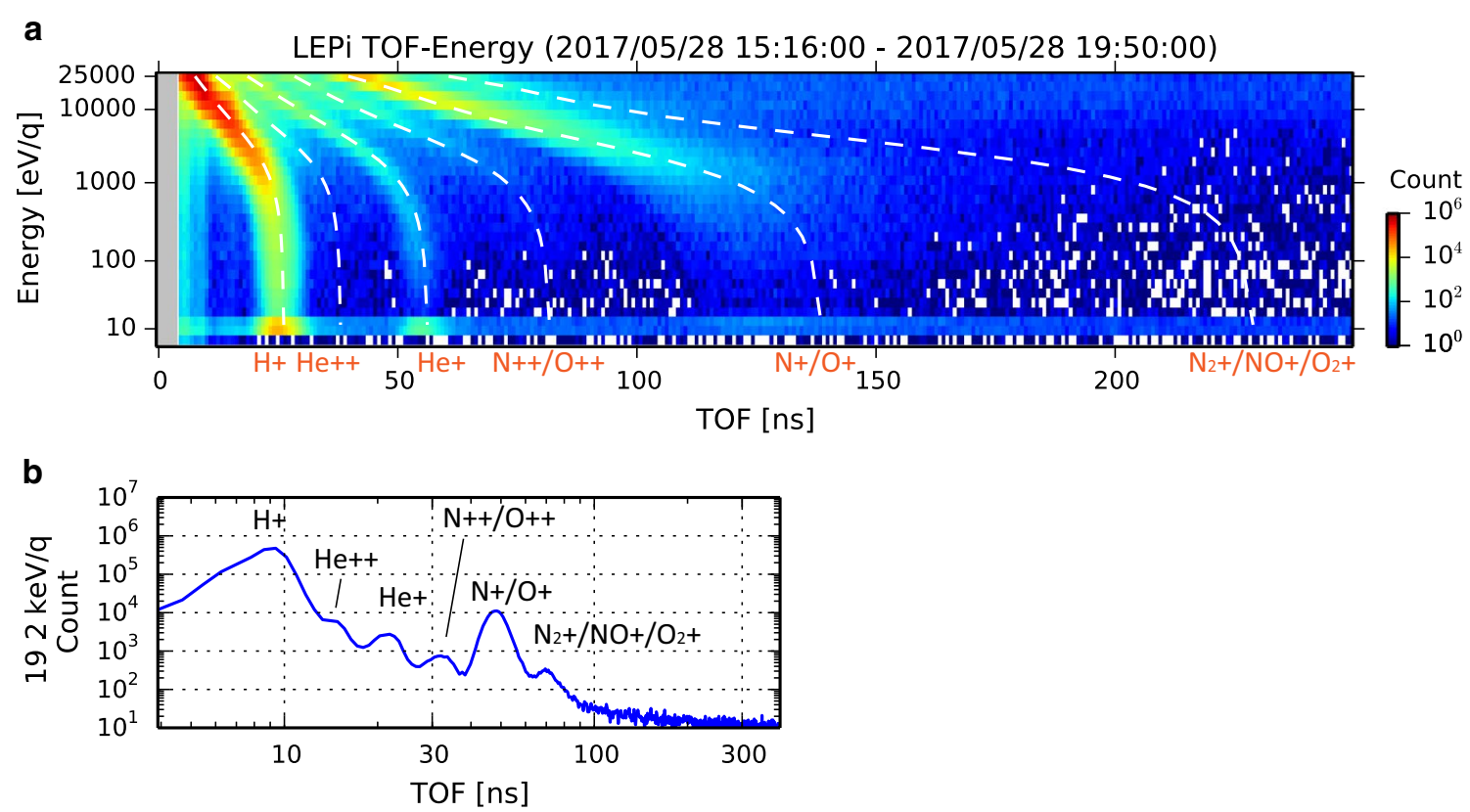

Fig. 17 a Energy (E/q)-TOF diagram observed at 1516-1950UT on May 28, 2017. The data are summed within the period. White dashed lines indicate the average TOF values obtained in laboratory experiments for $\mathrm{H}^{+}, \mathrm{H}_{2}^{+} / \mathrm{He}^{++}, \mathrm{He}^{+}, \mathrm{N}^{++}, \mathrm{N}^{+}$, and $\mathrm{N}_{2}^{+}$. b TOF spectrum with the energy of $19.2 \mathrm{keV} / \mathrm{q}$ 
background count rate is less than the minimum count rate of START ONLY and STOP ONLY events for each energy sweep. Therefore, by using Eq. $1, C_{\text {false }}$ due to the background $\left(C_{\mathrm{false}}\right.$ bg $)$ can be expressed as

$$
C_{\text {false,bg }} \leq C_{\text {startonly,min }}\left\{1-\exp \left(-C_{\text {stoponly,min }} \Delta T\right)\right\}
$$

where $C_{\text {startonly,min }}$ and $C_{\text {stoponly,min }}$ are the minimum count rates of the START ONLY and STOP ONLY events for each energy sweep, respectively. On May 28, 2017, $C_{\text {startonly,min }}$ and $C_{\text {stoponly,min }}$ are at most 8 and 93 [count/ sample], respectively. Therefore, $C_{\text {false,bg }}$ is less than 0.013 [count/sample]. Note that the sampling time is $14.6 \mathrm{~ms}$. The influence of the background noise is not significant on May 28, 2017.

Figure 17 shows the energy $(E / q)$-TOF diagram observed at 1516-1950 UT when LEPi is in the TOF mode. Accumulated counts during the period are shown in the panel. There are a large number of counts around the energy levels of $10 \mathrm{eV} / \mathrm{q}$, which comes mostly from the low-energy ionospheric/plasmaspheric component detected at 1516-1600 UT. Figure 17a shows $\mathrm{H}^{+}, \mathrm{He}^{++}$, $\mathrm{He}^{+}, \mathrm{N}^{++} / \mathrm{O}^{++}, \mathrm{N}^{+} / \mathrm{O}^{+}$, and $\mathrm{N}_{2}^{+} / \mathrm{NO}^{+} / \mathrm{O}_{2}^{+}$especially for higher energy levels. For reference, average TOF values observed in the laboratory experiment for each ion are indicated by white dashed lines. A TOF spectrum of ions with the energy of $19.2 \mathrm{keV} / \mathrm{q}$ is plotted in Fig. 17b, where count peaks of each ion are clearly identified. Based on the laboratory experiments, LEPi can discriminate $\mathrm{N}^{+}$ from $\mathrm{O}^{+}$and $\mathrm{N}^{++}$from $\mathrm{O}^{++}$, although their TOF spectra significantly overlap. However, there is no clear signature of two different components $\left(\mathrm{N}^{+}\right.$and $\mathrm{O}^{+}$, and/or $\mathrm{N}^{++}$ and $\mathrm{O}^{++}$) on May 28, 2017.

Molecular ions are observed in near-Earth (e.g., Taylor 1974; Hoffman et al. 1974; Klecker et al. 1986; Yaw et al. 1993; Peterson et al. 1994; Wilson and Craven 1999) and downtail regions (Christon et al. 1994; Poppe et al. 2016) associated with geomagnetic disturbance, although there are not many reports on the detection of molecular ions in the magnetosphere. The molecular ions are one of the typical constituents of the ionospheric lower $E$ region and they are often observed at higher altitudes above $500 \mathrm{~km}$ in the auroral and polar cap regions during geomagnetically active times (Taylor 1974; Hoffman et al. 1974; Yaw et al. 1993; Wilson and Craven 1998; Lennartsson et al. 2000). LEPi is expected to contribute to the understanding of the dynamics of the escape and transport of heavy ions, including molecular ions, in the magnetosphere.

\section{Summary}

LEPi has started its nominal observations successfully. LEPi is capable of observing three-dimensional velocity distribution functions of ions in the energy range of
$<0.01$ and $25 \mathrm{keV} / \mathrm{q}$ with species discrimination, such as $\mathrm{H}^{+}, \mathrm{He}^{++}, \mathrm{He}^{+}, \mathrm{N}^{++} / \mathrm{O}^{++}, \mathrm{N}^{+} / \mathrm{O}^{+}$, and $\mathrm{N}_{2}^{+} / \mathrm{NO}^{+} / \mathrm{O}_{2}^{+}$. Observations of LEPi are expected to contribute to the understanding of the ion dynamics and its relationship to the dynamics of high-energy electrons in the inner magnetosphere using other instruments onboard the ERG satellite, other satellites, and ground-based observations.

\section{Authors' contributions}

KA, YK, SY, and SK contributed to the design, fabrication, testing, and operation of the LEPi instrument. Initial observed data of LEPi were analyzed by KA and YM. All authors read and approved the final manuscript.

\section{Author details \\ 1 Japan Aerospace Exploration Agency, 3-1-1 Yoshinodai, Chuo, Sagami- hara 252-5210, Japan. ${ }^{2}$ Institute of Astronomy and Astrophysics, Academia Sinica, No. 1, Sec. 4, Roosevelt Rd, Taipei 10617, Taiwan, R.O.C... ${ }^{3}$ Osaka Uni- versity, Toyonaka, Osaka 560-0043, Japan. ${ }^{4}$ University of Tokyo, 7-3-1, Hongo, Bunkyo, Tokyo 113-0033, Japan. ${ }^{5}$ Institute for Space-Earth Environmental Research, Nagoya University, Furo, Chikusa, Nagoya 464-8601, Japan.}

\section{Acknowledgements}

The authors thank the ERG project team members for their development and operation of the ERG satellite. Discussions with D. Uchida, Y. Shirai, L. C. Liselott, C. S. Olsson, A. Imamura, and Y. Suto were useful for the development of LEPi. Components of LEPi were fabricated by Meisei Electric Co., Ltd., YS design, and Mitsubishi Heavy Industries, Ltd. The pitch angle distribution of particles was calculated under discussion with A. Matsuoka. The authors also thank Y. Shibano for her leading the effort which realizes most of the surface exposed to the space on ERG electrically conductive. All science data of the ERG project are distributed by the ERG-SC (https://ergsc.isee.nagoya-u.ac.jp/index.shtml).

\section{Competing interests}

The authors declare that they have no competing interests.

\section{Availability of data and materials}

The data and materials used in this study are available upon request. Please contact to the corresponding author. Both the AL and Sym-H indices are provided by WDC-C2, Kyoto University (http://wdc.kugi.kyoto-u.ac.jp/aeasy/).

\section{Ethics approval and consent to participate} Not applicable.

\section{Publisher's Note}

Springer Nature remains neutral with regard to jurisdictional claims in published maps and institutional affiliations.

Received: 14 September 2017 Accepted: 19 April 2018

Published online: 02 May 2018

\section{References}

Bürgi A, Oetliker M, Bochsler P, Geiss J (1990) Charge exchange of low-energy ions in thin carbon foils. J Appl Phys 68(6):2547-2554

Carlson CW, Curtis DW, Paschmann G, Michael W (1983) An instrument for rapidly measuring plasma distribution functions with high resolution. Adv Space Res 2:67-70

Chen L, Thorne RM, Jordanova VK, Horne RB (2010) Global simulation of magnetosonic wave instability in the storm time magnetosphere. J Geophys Res 115:A11222. https://doi.org/10.1029/2010JA015707

Christon SP, Gloeckler G, Williams DJ, Mukai T, McEntire RW, Jacquey C, Angelopoulos V, Lui ATY, Kokubun S, Fairfield DH, Hirahara M, Yamamoto $T$ (1994) Energetic atomic and molecular ions of ionospheric origin observed in distant magnetotail flow-reversal events. Geophys Res Lett 21(25):3023-3026 
Daglis IA, Thorne RM, Baumjohann W, Orsini S (1999) The terrestrial ring current: origin, formation, and decay. Rev Geophys 37(4):407-438

Fok M-C, Kozyra JU, Nagy AF, Cravens TE (1991) Lifetime of ring current particles due to Coulomb collisions in the plasmasphere. J Geophys Res 96(A5):7861-7867

Funsten HO, McComas DJ, Barraclough BL (1993) Ultrathin foils used for lowenergy neutral atom imaging of the terrestrial magnetosphere. Opt Eng 32(12):3090-3095

Funsten HO, Harper RW, McComas DJ (2005) Absolute detection efficiency of space-based ion mass spectrometers and neutral atom imagers. Rev Sci Instrum 76:053301. https://doi.org/10.1063/1.1889465

Funsten HO, Skoug RM, Guthrie AA, MacDonald EA, Baldonado JR, Harper RW, Henderson KC, Kihara KH, Lake JE, Larsen BA, Puckett AD, Vigil VJ, Friedel RH, Henderson MG, Niehof JT, Reeves GD, Thomsen MF, Hanley JJ, George DE, Jahn J-M, Cortinas S, Santos ADL, Dunn G, Edlund E, Ferris M, Freeman M, Maple M, Nunez C, Taylor T, Toczynski W, Urdiales C, Spence HE, Cravens JA, Suther LL, Chen J (2013) Helium, oxygen, proton, and electron (HOPE) mass spectrometer for the radiation belt storm probes mission. Space Sci Rev. https://doi.org/10.1007/s11214-013-9968-7

Gloeckler G, Hsieh KC (1979) Time-of-flight technique for particle identification at energies from 2-400 keV/nucleon. Nucl Inst Methods 165(3):537-544 Gruntman MA, Morozov VA (1982) H atom detection and energy analysis by use of thin foils and TOF technique. J Phys E Sci Instrum 15:1356-1358

Hoffman JH, Dodson WH, Lippincott CR, Hammack HD (1974) Initial ion composition results from the Isis 2 satellite. J Geophys Res 79(28):4246-4251

Horne RB, Wheeler GV, Alleyne HSCK (2000) Proton and electron heating by rapidly propagating fast magnetosonic waves. J Geophys Res 105(A12):27597-27610

Horne RB, Thorne RM, Glauert SA, Meredith NP, Pokhotelov D, Santolik $O$ (2007) Electron acceleration in the Van Allen radiation belts by fast magnetosonic waves. Geophys Res Lett 34:L17107. https://doi. org/10.1029/2007GL030267

Jordanova VK, Welling DT, Zaharia SG, Chen L, Thorne RM (2012) Modeling ring current ion and electron dynamics and plasma instabilities during a high-speed stream driven storm. J Geophys Res 117:A00L08. https://doi. org/10.1029/2011JA017433

Kasahara S, Yokota S, Mitani T, Asamura K, Hirahara M, Shibano Y, Takashima T (2018a) Medium-energy particle experiments-electron analyser (MEP-e) for the exploration of energization and radiation in geospace (ERG) mission. Earth Planets Space. https://doi.org/10.1186/s40623-018-0847-z

Kasahara Y, Kasaba Y, Kojima H, Yagitani S, Ishisaka K, Kumamoto A, Tsuchiya F, Ozaki M, Matsuda S, Imachi T, Miyoshi Y, Hikishima M, Katoh Y, Ota M, Shoji M, Matsuoka A, Shinohara I (2018b) The plasma wave experiment (PWE) on board the Arase (ERG) satellite. Earth Planets Space. https://doi. org/10.1186/s40623-018-0842-4

Kazama Y, Wang B-J, Wang S-Y, Paul TP, Sunny WY, Chang T-F, Chiang C-Y, Asamura K (2017) Low-energy electron instrument (LEPe) onboard the Arase spacecraft. Earth Planets Space. https://doi.org/10.1186/ s40623-017-0748-6

Kennel CF, Petschek HE (1966) Limit on stably trapped particle fluxes. J Geophys Res 71(1):1-28

Klecker B, Möbius E, Hovestadt D, Scholer M, Gloeckler G, Ipavich FM (1986) Discovery of energetic molecular ions $\left(\mathrm{NO}^{+}\right.$and $\mathrm{O}_{2}^{+}$) in the storm time ring current. Geophys Res Lett 13(7):632-635

Lennartsson OW, Collin HL, Ghielmetti AG, Peterson WK (2000) A statistical comparison of the outflow of ${ }_{2}^{+}, \mathrm{NO}^{+}$and $\mathrm{O}_{2}^{+}$molecular ions with that of atomic $\mathrm{O}^{+}$ions using polar/TIMAS observations. J Atmos Sol Terr Phys 62:477-483

Ma Q, Li W, Chen L, Thorne RM, Angelopoulos V (2014) Magnetosonic wave excitation by ion ring distributions in the Earth's inner magnetosphere. J Geophys Res 119:844-852. https://doi.org/10.1002/2013JA019591

Miyoshi Y, Sakaguchi K, Shiokawa K, Evans D, Albert J, Connors M, Jordanova $\checkmark$ (2008) Precipitation if radiation belt electrons by emic waves, observed from ground and space. Geophys Res Lett 35:L23101. https://doi. org/10.1029/2008GL035727

Miyoshi Y, Ono T, Takashima T, Asamura K, Hirahara M, Kasaba Y, Matsuoka A, Kojima H, Shiokawa K, Seki K, Fujimoto M, Nagatsuma T, Cheng CZ, Kazama Y, Kasahara S, Mitani T, Matsumoto H, Higashio N, Kumamoto A, Yagitani S, Kasahara Y, Ishizaka K, Blomberg L, Fujimoto A, Katoh Y, Ebihara Y, Omura Y, Nosé M, Hori T, Miyashita Y, Tanaka YM, Segawa T (2012) ERG working group: the energization and radiation in geospace (ERG) project.
In: Summers D, Mann IR, Baker DN, Schulz M (eds) Dynamics of the earth's radiation belts and inner magnetosphere, geophysical monograph, vol 199. American Geophysical Union, Washington, pp 103-116. https://doi. org/10.1029/2012GM001304

Peterson WK, Abe T, Fukunishi H, Greffen MJ, Hayakawa H, Kasahara Y, Kimura I, Matsuoka A, Mukai T, Nagatsuma T, Tsuruda K, Whalen BA, Yau AW (1994) On the sources of energization of molecular ions at ionospheric altitudes. J Geophys Res 99(A12):23257-23274

Poppe AR, Fillingim MO, Halekas JS, Raeder J, Angelopoulos V (2016) ARTEMIS observations of terrestrial ionospheric molecular ion outflow at the Moon. Geophys Res Lett 43:6749-6758. https://doi. org/10.1002/2016GL069715

Shoji M, Omura Y (2011) Simulation of electromagnetic ion cyclotron triggered emissions in the Earth's inner magnetosphere. J Geophys Res 116:A05212. https://doi.org/10.1029/2010JA016351

Shoji M, Miyoshi Y, Katoh Y, Keika K, Angelopoulos V, Kasahara S, Asamura K, Nakamura S, Omura Y (2017) lon hole formation and nonlinear generation of electromagnetic ion cyclotron waves: THEMIS observations. Geophys Res Lett. https://doi.org/10.1002/2017GL074254

Takashima T, Ogawa E, Asamura K, Hikishima M (2018) Design of mission network system with SpaceWire for scientific payloads onboard the Arase spacecraft. Earth Planets Space. https://doi.org/10.1186/ s40623-018-0839-z

Taylor HA Jr (1974) High latitude minor ion enhancements: a clue for studies of magnetosphere-atmosphere coupling. J Atmos Terr Phys 36:1815-1823

Thorne RM, Kennel CF (1971) Relativistic electron precipitation during magnetic storm main phase. J Geophys Res 76(19):4446-4453

Wilson GR, Craven P (1998) Under what conditions will ionospheric molecular ion outflow occur? In: Horwitz JL, Gallagher DL, Peterson WK (eds) Geospace mass and energy flow: results from the international solarterrestrial physics program, geophysical monograph, vol 104. American Geophysical Union, Washington, pp 85-95

Wilson GR, Craven P (1999) Molecular ion upflow in the cleft ion fountain. J Geophys Res 104(A3):4437-4446

Wurz P (2000) Detection of energetic neutral atoms. In: Scherer K, Fichtner H Marsch E (eds) The outer heliosphere: beyond the planets. Copernicus Gesellschaft, Katlenburg-Lindau, pp 251-288

Yaw AW, Whalen BA, Goodenough C (1993) EXOS D (Akebono) observations of molecular $\mathrm{NO}^{+}$and $\mathrm{O}_{2}^{+}$upflowing ions in the high-altitude ionpshere. J Geophys Res 98(A7):11205-11224

Yokota S, Kasahara S, Mitani T, Asamura K, Hirahara M, Takashima T, Yamamoto K, Shibano Y (2017) Medium-energy particle experiments-ion mass analyzer (MEP-i) onboard ERG. Earth Planets Space. https://doi.org/10.1186/ s40623-017-0754-8

\section{Submit your manuscript to a SpringerOpen ${ }^{\circ}$ journal and benefit from:}

- Convenient online submission

- Rigorous peer review

- Open access: articles freely available online

- High visibility within the field

- Retaining the copyright to your article

Submit your next manuscript at $\boldsymbol{\nabla}$ springeropen.com 